\title{
TRATAMIENTO DE LA KAFALA EN ESPAÑA Y POSTERIOR CONSTITUCIÓN DE UNA ADOPCIÓN. LEY NACIONAL DEL MENOR QUE PROHIIBE LA ADOPCIÓN: FLEXIBILIZACIÓN DE LA CLÁUSULA LIMITATIVA (AUTO DE LA AP DE CÁDIZ [SECCIÓN 5ª] DE 27 DE NOVIEMBRE DE 2021)
}

\author{
THE KAFALA INSTITUTION IN SPAIN AND THE \\ CONSTITUTION OF INTERNATIONAL CHILD ADOPTION. \\ ARTICLE 19.4 OF THE SPANISH ACT 54/2007
}

\author{
Mónica Herranz Ballesteros \\ Profesor Titular \\ UNED (Universidad Nacional de Educación a Distancia) \\ ORCID ID: 0000-0002-0748-6598
}

Recibido: 02.07.2021 / Aceptado: 19.07.2021

DOI: https://doi.org/10.20318/cdt.2021.6293

Resumen: Constitución de una adopción internacional sobre un menor de nacionalidad marroquí en régimen de Kafala. Solicitantes españoles con residencia habitual en España. Silencio por parte del órgano juzgador en torno a la prohibición del artículo 19.4 de la LAI. Modulación de la cláusula limitativa.

Palabras clave: Kafala, constitución de adopción internacional, artículo 19.4 de la Ley de adopción internacional

Abstract: International adoption in Spain of a marroquian child after a Kaflah in her country of origin. Spanish citizens with habitual residence in Spain. The application of article 19.4 of the International Adoption Law in such cases.

Keywords: Kafala, international child adoption, article 19.4 of the International Adoption Law

Sumario: I. Introducción. II. Hechos. III. El auto de la AP de Cádiz de 27 de noviembre del 2021 1. Razonamientos jurídicos a los que se refiere la decisión 2. Razonamientos jurídicos que elude la decisión: ley nacional del menor que prohíbe la adopción y su posible flexibilización IV. Conclusiones.

\section{Introducción}

1. La Kafala ha sido, y es tratada en la actualidad como una institución desconocida dado que, tal y como se concibe en el derecho extranjero, no es una medida contenida en el ordenamiento español, por lo que es necesario buscar una institución española en la que encaje. Sin embargo, el desconocimiento no alcanza ni a nuestras autoridades, habituadas ya a resolver situaciones en las que 
ha sido constituida una Kafala transnacional ${ }^{1}$, ni a la doctrina especializada que se ha ocupado de ella de forma minuciosa ${ }^{2}$.

2. Ahora bien, siendo una figura no contenida de manera expresa en el derecho español ${ }^{3}$, es cierto que la modificación del artículo 19 de la Ley 54/2007, de 28 de diciembre, de Adopción Internacional (en adelante LAI) ${ }^{4}$ en el año $2015^{5}$ dio respuesta, en principio, a la problemática que presentaba la Kafala, representando una solución al compromiso del Estado español frente a las autoridades marroquíes con objeto de impedir la adopción en España de menores sobre los que se había constituido una Kafala transnacional ${ }^{6}$.

Textualmente el precepto indica: "4. En el caso de menores cuya ley nacional prohíba o no contemple la adopción se denegará la constitución de la adopción, excepto cuando el menor se encuentre en situación de desamparo y tutelado por la Entidad Pública”.

De una lectura del precepto resulta como la prohibición no distingue entre menores extranjeros que residan en el extranjero o que residan en España, por tanto, conforme a su literalidad la limitación se extiende a todos cuando su ley nacional prohíbe o no contemple la adopción ${ }^{7}$. Además, esta norma, calificada como imperativa, conlleva que decaiga en su caso la competencia atribuida a la autoridad

\footnotetext{
* El presente trabajo se adscribe al Proyecto PID2020-114611RB-I00, "PROTECCION DEL MENOR EN LAS CRISIS FAMILIARES INTERNACIONALES. (ANALISIS DEL DERECHO INTERNACIONAL PRIVADO ESPAÑOL Y DE LA UNION EUROPEA)" concedido por el Ministerio de Ciencia e Innovación.

' En 2006 la DGRN sentó las bases para la calificación de la kafala en la Resolución Circular de 15 de julio de 2006 sobre reconocimiento e inscripción en el Registro Civil español de las adopciones internacionales BOE núm., 207, de 30.08.2006.

${ }^{2}$ Hay numerosos trabajos dedicados a esta institución solo a modo de ejemplo, P. DiAgo DiAgo, "La kafala islámica en España. $C D T$, vol. 2, no 1, marzo 2010, p. 142. S. AdroHer BIOSCA, "Un estudio de caso sobre adoptabilidad: la kafala islámica», Se busca familia para un niño. Perspectivas psico-jurídicas sobre la adoptabilidad, (B. Gómez Bengoechea, A. Berástegui Pedro-Viejo, S. Adroher Biosca), Madrid, Dykinson, Comillas. 2015; ibid., "La kafala islámica: ¿medida de protección de menores o estrategia migratoria? Revista de Derecho migratorio y de extranjería no 45, 2017, pp. 203-220. C. RuIz SuTIL., "La mujer Kafila y la recepción de la Kafala en el ordenamiento español”, Revista Clepsydra, 16, noviembre 2017, pp. 145-166. La Kafala ha dado lugar a distintas cuestiones de las que la doctrina también se ha ocupado, a modo de ejemplo, desde la perspectiva de la posibilidad de obtener un visado por reagrupación familiar de un menor sometido a Kafala, vid., M. VARGAS UrRutia, "La kafala del Derecho musulmán y el Tribunal Supremo", El Tribunal Supremo y el Derecho internacional privado. Vol. 2. (A. L. Calvo Caravaca / J. Carrascosa González, Dirs), Colección Derecho y Letras, núm. 1, Murcia, 2019, p. 475-488; o en relación a la protección social, por ejemplo, a efectos del cobro de una pensión de orfandad, vid., G.M. Quintero LiMA., "Globalización y Seguridad Social: sentencias sobre Kafala y pensión de orfandad", Revista General de Derecho del Trabajo y la Seguridad Social 17, 2008.

${ }^{3}$ Sí está prevista en textos internacionales como en el artículo 20.3 de la Convención de Naciones Unidas sobre los Derechos del Niño de 1989. En Derecho internacional privado convencional se incluye en el artículo 3 letra c) del Convenio de La Haya de 19 de octubre de 1996, relativo a la competencia, la ley aplicable, el reconocimiento, la ejecución y la cooperación en materia de responsabilidad parental y medidas de protección de los niños y su reconocimiento, como medida de protección es posible entre Estados parte del Convenio a través del artículo 23 respetando las condiciones del precepto.

4 BOE núm., 312 de 29.12.2007.

5 Se modifica a través de la Ley 26/2015, de 28 de julio, de modificación del sistema de protección a la infancia y a la adolescencia, BOE núm., 180 de 29.07.2015.

${ }^{6}$ Es bien conocida la Circular ${ }^{\circ} 40 \mathrm{~S} / 2$ del Ministro de Justicia y de las libertades marroquí de julio de 2012. Un comentario a la misma de P. DiAGo DiAGo http://www.millenniumdipr.com/e-68-5-n\%C2\%BA-2-denegacion-deconstitucion-de-kafalapor-parte-de-extranjeros-que-no-residenhabitualmente-en-marruecos-circular-n $\% \mathrm{C} 2 \% \mathrm{BA}-40$-s-2-reino-demarruecos

Para una visión del panorama anterior a la modificación de la LAI vid., C.I. Cordero AlvÁrez, "Adopción en Europa y efectos de la Kafala en el marco del Convenio Europeo de Derechos Humanos”, AEDIPr., Tomo XII, 2012, pp. 455-489.

${ }^{7}$ Crítica con la modificación del art. 19 de la LAI se muestra E. Rodríguez Pineau., "La protección en España de menores cuya ley nacional prohíbe la adopción tras la reforma de la Ley 54/2007 de Adopción internacional”, Derecho Privado y Constitución, 31 enero/diciembre (2017), pp. 387-415.

Esta prohibición no es novedosa en el derecho comparado. El ordenamiento francés la contiene en el artículo 370-3 del Cc precepto al que hay que añadir la posterior reforma a través de una Circular del Ministerio de Justicia de 2014. Y el ordenamiento belga en el artículo 361-5 del Cc. Analizadas por E. Rodríguez Pineau, pp. 400-403. M. Herranz Ballesteros, "La búsqueda de la armonía internacional de soluciones: ¿un objetivo a cualquier precio en materia de adopción internacional?", El derecho de familia ante el Siglo XXI: aspectos internacionales. (Dir. Calvo Caravaca, A.L., Castellanos Ruiz, E.,), Colex, 2004, pp. 487-510.
} 
competente para constituir la adopción ${ }^{8}$. Ahora bien, como se verá a continuación, esta limitación se modula o suaviza cuando se cumplen ciertas condiciones.

3. Así, junto al anterior precepto es importante, por la proyección que ha tenido y tiene en la práctica, el Dictamen 3/2016, sobre la incidencia de la reforma de la Ley 54/2007, de 28 de diciembre, de Adopción Internacional, respecto al tratamiento de la kafala de la Fiscalía General del Estado?.

A través del referido Dictamen la Fiscalía determina el ámbito de aplicación de la cláusula limitativa del artículo 19.4 de la LAI. El precepto se aplica: a los supuestos en los que el ordenamiento de la nacionalidad del menor limite o no contenga la adopción siempre que éste conserve su nacionalidad de origen. Sensu contrario, conforme al citado Dictamen, la limitación o prohibición no resulta aplicable cuando el menor: adquiere la nacionalidad española o está en situación de desamparo o tutelado por la Administración pública, aunque el derecho extranjero no contenga o prohíba la adopción. Además, hay que apuntar que la prohibición, en principio, tampoco será operativa cuando se trate de un menor emancipado o un mayor de edad ${ }^{10}$.

4. Desde una perspectiva autonómica, y en relación a este aspecto, la Ley 25/2010, de 29 de julio, del Libro II del Código civil de Cataluña, relativo a la persona y a la familia ${ }^{11}$, en su subsección cuarta, relativa a la adopción y acogimiento internacional de menores, art. 235-44-4 contiene un precepto relacionado directamente con el contenido del art. 19.4 de la LAI:

"La autoridad judicial puede disponer, de modo excepcional, respecto a menores en cuyos países de origen no exista la adopción ni ninguna otra institución equivalente, la constitución de la adopción en aquellas situaciones análogas al acogimiento o a la tutela, constituidas en el extranjero con finalidad protectora permanente. Son requisitos imprescindibles que la constitución de la adopción sea necesaria para el interés del menor, que lo permitan las normas de derecho internacional privado aplicables y que la entidad pública competente de la residencia de la familia emita el certificado de idoneidad respecto a la persona o personas que lo tienen confiado y solicitan su adopción".

El ámbito de aplicación del referido precepto se refiere de forma expresa a los casos en los que en el ordenamiento extranjero no exista la adopción, por tanto, no se incluyen los supuestos que, como en el art. 19.4 de la LAI, el ordenamiento extranjero prohíba la adopción. Además, la propia norma da soluciones de encaje en la medida que, aunque sea de forma excepcional, capacita a la autoridad competente para constituir una adopción supeditando su decisión al cumplimiento de las siguientes condiciones: primero, que lo permitan las normas de derecho internacional privado, es decir a través de esta remisión se da entrada a los artículos de la LAI (art. 18 y 19, de particular importancia en este caso el apartado 4) ${ }^{12}$; segundo, la emisión del certificado de idoneidad por la entidad pública competente; y tercero que la misma responda al interés del menor, circunstancia que en estos casos y conforme a la jurisprudencia viene a coincidir con la integración del mismo en la familia con la que lleva ya conviviendo un tiempo.

8 Vid., M. GuZmÁn ZaPATER., "La adopción consular tras la reforma de la Ley 26/20015”, BIMJ, (en prensa). La AP de Valencia (Sección $10^{\mathrm{a}}$ ) en Auto $\mathrm{n}^{\circ}$ 175/2020 de 5 de mayo cierra la posibilidad de argumentar la contrariedad con el orden público español de la ley extranjera que prohíbe la adopción, tampoco empleando argumento del recurrente de que dicho ordenamiento extranjero no respeta el interés del menor. Como expresa la Audiencia es la propia ley española la que prohíbe la adopción en estos casos ECLI:EU:APV:2020:1104A.

9 Previamente la Fiscalía había dictado la Circular 8/2011 sobre criterios para la unidad de actuación especializada del Ministerio Fiscal en materia de protección de menores, estableciendo sus conclusiones sobre el tratamiento de la kafala en su Apdo. XII.

${ }^{10}$ En este sentido véase M. GuZMÁn ZAPATER, "Kafala y Derecho español tras la reforma de la Ley 54/2007. A propósito del Auto AP de León de 27 de junio de 2019” CDT (Octubre 2020), Vol. 12, No 2, p. 1040. En relación con la aplicación de la norma sobre menores emancipados y mayores de edad vid., A.L. Calvo CaravaCa/J. Carrascosa González, La Ley 54/2007 de 28 de diciembre 2007 sobre adopción internacional (Reflexiones y comentarios), Comares, Granada, 2008, pp. 43-44.

11 BOE núm., 203 de 28.08.2010.

${ }_{12}$ Véase sobre la aplicación de la norma autonómica y su remisión a las normas de DIPR la decisión de la AP de Barcelona (Sección 18a), Auto núm., 2202/2020 de 10 de junio. ECLI: ES:APB:2020:4271A. Igualmente una aplicación no acertada del precepto se hace por AP de Gerona (Sección 1ª) de 18 de diciembre de 2017, Auto núm., 247/2017 ECLI:ES:APGI:2017:1116A. 
5. Con lo anterior hemos tratado de dibujar de forma previa y breve la situación existente en España. Es el momento de analizar ahora cómo ha procedido, en su caso, la AP de Cádiz (Sección $5^{\mathrm{a}}$ ) en su Auto núm., 243/2020 dictado el 27 de noviembre del $2021^{13}$.

\section{Hechos}

6. Los supuestos más habituales que se presentan a las autoridades españolas se dividen en dos situaciones que aun respondiendo a una realidad bastante parecida en algunos casos obtienen diferentes soluciones en la práctica ${ }^{14}$. Los rasgos comunes en la práctica habitual son: constitución de Kafalas sobre menores por parte de autoridades extranjeras y el posterior traslado de éstos a España (han venido a denominarse Kafalas transnacionales distintas de las Kafalas internacionales). Pero la diferencia está en que en unos casos quienes constituyen la Kafala son nacionales españoles, y en otros casos las Kafalas se constituyen por nacionales de los Estados donde la medida fue establecida ${ }^{15}$. En ambos supuestos son Kafalas transnacionales, es decir el menor es desplazado desde su lugar de origen a España, que es el Estado de residencia habitual de los kafiles.

7. El caso objeto de análisis está dentro del primero modelo o supuesto. Los datos son: un menor de edad de nacionalidad marroquí y con residencia habitual en Marruecos es declarada en abandono mediante decisión adoptada por un Tribunal de Primera Instancia marroquí en 2016. Los adoptantes, nacionales españoles, se acogieron a las normas de la Kafala y el menor les fue entregado constituyendo, por auto de 8 de marzo de 2017, una tutela dativa. La menor es entregada un mes más tarde a los hoy adoptantes quienes junto a la niña se trasladan a Ceuta el mismo 2017.

Tres años después de que la menor viajara a España desde Marruecos se insta la constitución de la adopción, medida que se acuerda por el juez de primera instancia el 27 de noviembre de 2020. Frente a este auto el Ministerio Fiscal interpone recurso de apelación ante la Audiencia Provincial de Cádiz, quien resuelve por auto dictado el 27 de noviembre del 2021.

\section{El auto de la AP de Cádiz de 27 de noviembre del 2021}

8. Como puede observarse los hechos son similares a los que de forma habitual caracterizan a los supuestos que se presentan a las autoridades españolas en relación con menores sobre quienes se ha constituido una Kafala judicial por autoridades extranjeras, en este caso marroquíes.

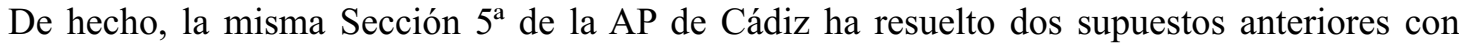
idénticos datos y con el mismo iter judicial: aprobación de la adopción en primera instancia, recurso presentado por el Ministerio Fiscal, desestimación del recurso en segunda instancia confirmando, por tanto, la decisión dictada en instancia por la que se aprobaba la adopción ${ }^{16}$.

9. En definitiva, se plantea a la AP de Cádiz la petición de adopción de una menor residente en España en compañía de los solicitantes que tienen la guarda y cuidado sobre la misma y a quienes se ha otorgado la tutela dativa por autoridades judiciales extranjeras. Para resolver la Audiencia se cuestiona: primero, ¿cuál es la legislación aplicable?, segundo, ¿a qué institución de protección de menores española debe asimilarse la Kafala constituida por las autoridades extranjeras?

\footnotetext{
13 JUR/2021/5329.

${ }_{14}$ Nos referimos a las situaciones que se presentan con las kafalas judiciales y no a los supuestos de las kafalas notariales que en mayor medida se constituyen por familiares del menor que residen en España. Brevemente sobre las diferencias entre ambas vid., E. Rodríguez Pineau., "La protección en España de menores”, op. cit., p. 392. C. Ruiz Sutil., "La mujer Kafila y la recepción de la Kafala...", op. cit., p. 148.

${ }^{15}$ Ejemplo de S. Adroher Biosca., "Kafala y adopción. El auto de la AP de Barcelona (Sección 18a) No 220/2020 de 10 de junio", CDT, (Marzo 2021), Vol. 13, № 1, pp. 694-701. Ma J. SANCHÉz CANO., “Adopción de menores en situación de Kafala y la ley nacional del adoptando", CDT., (Octubre 2018), Vol. 10, № 2, pp. 931-946; M. GuZmán Zapater, "Kafala y Derecho español...", op. cit.

${ }^{16}$ AP de Cádiz (Sección 5a) Auto núm., 72/2018 de 12 de marzo, ECLI:ES:APCA:2018:561A; AP de Cádiz (Sección $5^{\mathrm{a}}$ ) Auto núm., 254/2020 de 11 de octubre, ECLI:ES:APCA:2020:1500A.
} 


\section{Razonamientos jurídicos a los que se refiere la decisión}

10. Comenzando por el segundo de los interrogantes relativo a la institución española a la que debe de equipararse la Kafala, la AP recurre a la Resolución de la Dirección General de Registros y del Notariado de 15 de Julio de $2006^{17}$ en la que se califica por función a la institución de la Kafala asimilándola al acogimiento familiar. En consecuencia, la menor que había sido entregada a los ahora solicitantes en el año 2017 residía en España bajo ese régimen desde hacía más de tres años.

11. En torno al instrumento jurídico aplicable, la AP de Cádiz se remite a las previsiones de la Ley de Adopción Internacional. En primer lugar, deja clara la competencia de las autoridades españolas refiriéndose al artículo 14 de la LAI. En segundo lugar, en torno al derecho aplicable, se remite a los artículos 18 y 19, en particular para sostener la aplicación de la ley española a la adopción se basa en el apartado a) del artículo 18 y el artículo 19.1 letra b), dado que el menor tiene su residencia en España y adquiere la nacionalidad española en virtud de la adopción. En consecuencia, tanto la constitución de la adopción, la capacidad del adoptando como los consentimientos se regirán por la ley española.

El expediente de constitución de la adopción se tramitará conforme a las previsiones de la Ley 15/2015, de 2 de julio, de la Jurisdicción Voluntaria (art. 33 y siguientes de la LJV). Teniendo en cuenta los datos anteriores el proceso dará comienzo con la propuesta de adopción que se presenta directamente por los interesados mediante escrito.

La solicitud de manera directa por los interesados solo es posible en casos excepcionales dado que en la mayoría de los supuestos es necesaria la propuesta previa de la Entidad Pública competente (art. 176 del Cc y art. 35.3 LJV). El caso objeto de comentario, tal y como sostiene la AP de Cádiz, se encuentra entre aquellos que no precisan dicha propuesta, es decir no es necesario dado que el supuesto se encuentra entre los recogidos en el apartado 3 del artículo 176.2 del Cc. Ahora bien, que no sea necesaria la propuesta previa no quiere decir que la autoridad competente no tenga que cerciorarse de las condiciones de idoneidad de los adoptantes y que se cumplen los requisitos que la ley exige.

\section{Razonamientos jurídicos que elude la decisión: ley nacional que prohíbe la adopción y su flexi- bilización}

12. Aunque la AP de Cádiz se refiere a distintos apartados de los artículos 18 y 19 de la LAI no alude a la prohibición contenida en el artículo 19.4; limitación que sobrevuela el supuesto, dado que la ley marroquí prohíbe la adopción ${ }^{18}$. Por tanto, la cuestión es: ¿la decisión de la AP de Cádiz que confirma el auto de primera instancia y, por tanto, declara la constitución de la adopción es acorde con la norma? Como indicamos poco puede extraerse del auto dictado por el referido Tribunal. Tampoco hay referencia alguna al motivo por el que el Ministerio Fiscal presenta recurso ${ }^{19}$.

13. La flexibilización de la norma, y en su caso la posibilidad de constituir la adopción en estas situaciones, entendemos es posible teniendo en cuenta la interpretación que de la limitación del artículo 19.4 de la LAI ha hecho la FGE en el citado Dictamen 3/2016 (vid., supra apartado I).

Conforme al mismo la prohibición del artículo 19.4 opera cuando el menor conserve su nacionalidad de origen, no siendo aplicable, entre otros casos, si adquiere la nacionalidad española. ¿Quiere decir esta afirmación qué la limitación no es aplicable cuando el menor adquiere la nacionalidad espa-

\footnotetext{
17 BOE núm. 207, de 30.08.2006.

18 Sí se menciona el art. 19.4 de la LAI al oponerse el Ministerio Fiscal a la constitución de una adopción en base a la prohibición contenida en la ley marroquí. Sin embargo, la AP de las Islas Baleares (Sección $4^{\text {a }}$ ) Auto n $173 / 2017$ expresa que tal ordenamiento no prohíbe la adopción, sino que no la completa. Y en base a lo anterior procede a la constitución de la adopción en España. ECLI:ES:APIS:2017:315A. Se refiere expresamente al referido precepto y deniega la constitución de la adopción la AP de Logroño (Sección $3^{a}$ ) Auto no 173/2021, ECLI:ES:APLO:2021:173A.

19 Referencia que tampoco aparece en los Autos ya mencionados de la misma Audiencia (vid., supra., nota al pie núm., 16.
} 
ñola por la adopción (art. 19.1 del Cc)? o ¿qué la limitación no opera cuando el menor podría adquirir la nacionalidad española por otra vía?

La primera opción, conlleva considerar español al menor al constituir la adopción. Es decir, aplicar la ley española como ley nacional presunta que adquirirá por la adopción (art. $19.1 \mathrm{del} \mathrm{Cc})^{20}$. Este enfoque no parece que se corresponda con la interpretación que ha de darse al Dictamen de la FGE en la medida que, como algún autor ha indicado, éste evitaría la práctica anterior de anticipar la aplicación de la ley española como ley de la futura nacionalidad del adoptando (si el kafil fuera español) ${ }^{21}$.

La segunda opción, supondría que la limitación no operaría cuando el menor hubiera podido adquirir la nacionalidad por otra vía distinta a la tesis o teoría de la nacionalidad anticipada, lo que sería posible, por ejemplo, cuando el menor en régimen de Kafala llevara un año de residencia en España y hubiera estado en acogimiento por persona o institución española durante dos años consecutivos (art. 22.1 $\mathrm{CC}$ ). Esta podría ser la solución aplicable a este supuesto dado que la menor lleva en situación de acogimiento por españoles desde abril de 2017 y, en consecuencia, la adquisición de la nacionalidad por la vía indicada es posible cuando, como en este caso, los kafiles sean españoles y representes legales del menor ${ }^{22}$.

14. Esta segunda opción encaja con el supuesto analizado; ahora bien, del Auto de la AP de Cádiz no podemos extraer qué razonamiento siguió dado que no se refiere a la prohibición contenida en la ley nacional de la menor y contemplada por el artículo 19.4 de la LAI.

\section{Conclusiones}

15. Los hechos responden a datos tradicionales en la práctica española: nacionales españoles con residencia en España que constituyen una Kafala en el país de origen del menor y posterior traslado del mismo a España. Si bien es cierto que junto a los supuestos anteriores hay otros que se están volviendo también habituales, como la constitución de una Kafala por residentes españoles pero nacionales del Estado de constitución y traslado posterior a España del menor.

16. La actuación de la AP de Cádiz en estos casos, al menos en los últimos tiempos ha sido bastante parecida: en primera instancia se insta la constitución de la adopción. El Ministerio Fiscal se opone presentando recurso ante la AP y finalmente ésta acepta el recurso confirmando la decisión en instancia.

La AP ha seguido la calificación por función de la Kafala como acogimiento y en estos casos ha sostenido como no es necesaria la Propuesta previa de la Entidad pública competente; por tanto, se admite la actuación directa de los solicitantes. Ahora bien, ello no quita que no sea necesario obtener la información que requiere la norma sobre los adoptantes.

También es cierto que en este Auto y en los anteriores la AP de Cádiz no se ha referido a la prohibición de adopción del artículo 19.4 de la LAI, aunque estemos en un supuesto en el que la ley nacional de la menor prohíba la adopción. Pero, como hemos visto la modulación de dicha cláusula a través de las directrices dadas por la Fiscalía General es posible, de manera que la prohibición no será aplicable cuando el menor adquiere la nacionalidad española, inclinándonos por la opción que descarta la aplicación anticipada de la ley española por la adopción, pero que permite acudir a otras vías como la indicada.

17. En definitiva, creemos que la actuación de la AP de Cádiz ha sido correcta, aunque hay muchos aspectos que no quedan reflejados en la decisión y que deberían de haberse planteado de forma expresa en el Auto comentado.

\footnotetext{
${ }^{20}$ En relación a la conexión anticipada vid., M. Herranz Ballesteros, "La búsqueda de la armonía internacional de soluciones:...", op. cit., p. 508.

${ }^{21}$ E. Rodríguez Pineau, "La protección en España de menores cuya ley nacional prohíbe la adopción..., op. cit., p. 408.

${ }^{22}$ Sobre este aspecto véase el Dictamen de la FGE cuando afirma: "Cuando la kafala ha sido constituida por la autoridad pública competente del país de origen con fundamento en una previa situación de abandono, debe partirse de la atribución de la representación legal del menor a su acogedor".
} 